\title{
PEMANFAATAN ENDORSE DAN HASHTAG UNTUK PEMASARAN PRODUK MENGGUNAKAN INSTAGRAM PADA UMKM DI KECAMATAN PATUK KABUPATEN GUNUNG KIDUL
}

\author{
Nurcahyani Dewi Retnowati ${ }^{1}$, Yuliani Indrianingsih ${ }^{2}$, \\ Anton Setiawan Honggowibowo ${ }^{3}$ \\ Program Studi Teknik Informatika \\ Sekolah Tinggi Teknologi Adisutjipto \\ Jl. Janti Blok R Adisuipto Yogyakarta \\ Email: ${ }^{1}$ nurcahyanidr@stta.ac.id, ${ }^{2}$ yulistta@gmail.com, ${ }^{3}$ anton@stta.ac.id
}

\begin{abstract}
Abstrak
Usaha Mikro, Kecil dan Menengah (UMKM) merupakan usaha yang berkembang di masyarakat dan dapat meningkatkan pertumbuhan ekonomi Indonesia. UMKM tersebut tersebar di banyak daerah, tak terkecuali di Kecamatan Patuk Kabupaten Gunung Kidul dan bergerak di bidang produk dan jasa. Sampai saat ini, pemasaran produk yang dilakukan oleh para pelaku UMKM di Kecamatan Patuk adalah pemasaran konvensional yaitu pemasaran produk melalui relasi di lingkungan pelaku usaha. Sehingga sangat penting untuk dilakukan peningkatan pemasaran produk dengan menggunakan pemasaran online yang berbasis pada media sosial, salah satunya dengan menggunakan Instagram. Penggunaan Instagram sebagai media pemasaran juga membutuhkan adanya pemanfaatan endorse dan hashtag untuk lebih mengoptimalkan pemasaran. Oleh karena itu, UMKM di Kecamatan Patuk memerlukan pelatihan tentang bagaimana memanfaatkan Instagram sebagai strategi dalam memasarkan, khususnya tentang bagaimana memanfaatkan endorse dan hashtag sehingga diharapkan pemasaran menjadi lebih optimal dan tepat sasaran. Untuk memenuhi kebutuhan mitra (para pelaku UMKM) dilakukan pendampingan pemanfaatan endorse dan hashtag pada media sosial Instagram sebagai media pemasaran produk oleh pelaksana pengabdian kepada masyarakat yang merupakan Dosen Program Studi Teknik Informatika Sekolah Tinggi Teknologi Adisutjipto. Pendampingan tersebut dapat meningkatkan kemampuan pelaku UMKM di Kecamatan Patuk dalam memanfaatkan endorse dan hashtag menggunakan Instagram sebagai salah satu upaya dalam meningkatkan pemasaran produk. Hasil kegiatan pengabdian menunjukkan bahwa $10 \%$ peserta pengabdian belum dapat memanfaatkan Instagram secara optimal dikarenakan peserta tersebut hanya datang pada hari pertama saja, $20 \%$ peserta pengabdian sudah dapat memanfaatkan Instagram dengan baik namun belum optimal dalam menggunakan endorse dan hashtag, dan $70 \%$ peserta pengabdian sudah sangat optimal menggunakan Instagram dan memanfaatkan endorse dan hashtag.
\end{abstract}

Kata Kunci: endorsement, hashtag, pemasaran produk, pemasaran online

\section{Abstract}

Micro, Small and Medium Enterprises (MSMEs) are businesses that develop in the community and can increase Indonesia's economic growth. These MSMEs are spread in many areas, including the Patuk District in Gunung Kidul Regency and are engaged in products and services. Until now, the marketing of products carried out by SMEs in Patuk District is conventional marketing, which is marketing products through relationships within the business community. So it is very important to increase product marketing by using online marketing based on social media, one of which is using Instagram. The use of Instagram as a 
marketing medium also requires the use of endorse and hashtags to further optimize marketing. Therefore, SMEs in Patuk Subdistrict need training on how to use Instagram as a marketing strategy, especially on how to utilize endorse and hashtag so that marketing is expected to be more optimal and targeted. To meet the needs of partners (UMKM actors), mentoring is used in the use of endorse and hashtags on Instagram social media as a product marketing medium by implementing community service, which is a lecturer in the Informatics Engineering Study Program at Adisutjipto College of Technology. This assistance can improve the ability of SMEs in Patuk District to utilize endorse and hashtag using Instagram as an effort to improve product marketing. The results of the community service activities show that $10 \%$ of community service participants have not been able to use Instagram optimally because they only come on the first day, $20 \%$ of community service participants have been able to use Instagram well but have not been optimal in using endorse and hashtag, and $70 \%$ of community service participants have very optimal using Instagram and utilizing endorse and hashtag

Keywords : endorsement, hashtag, product marketing, online marketing

\section{Latar Belakang Masalah}

Usaha Mikro, Kecil dan Menengah (UMKM) merupakan usaha produktif yang berkembang di masyarakat dan berperan dalam penyerapan tenaga kerja yang tidak sedikit dan membantu pemerintah dalam mengurangi jumlah angka pengangguran [1]. UMKM juga memberikan kontribusi dalam pertumbuhan ekonomi Indonesia [2] sebesar 60\% [3] serta berperan dalam pendistribusian hasil-hasil pembangunan [4]. membutuhkan dukungan dari pemerintah.

Sebelum melakukan pelatihan dan pendampingan, dilakukan survey terlebih dahulu yang bertujuan untuk mengetahui bagaimana permasalahan yang dihadapi oleh mitra atau peserta pengabdian [5]. Permasalahan mitra dalam hal ini UMKM di Kecamatan Patuk Kabupaten Gunung Kidul adalah pada pemasaran produk untuk penjualan. Pemasaran suatu produk erat kaitannya dengan strategi promosi dan dengan promosi konvensional dirasa kurang efektif karena berimplikasi dengan biaya yang akan dikeluarkan [6]. Strategi promosi pemasaran produk yang biayanya terjangkau dan dapat menjangkau masyarakat luas dapat menggunakan media sosial, salah satunya dengan menggunakan Instagram [7].

Saat ini peningkatan jangkauan pemasaran dan volume penjualan dapat dilakukan dengan internet marketing atau social media. Social media yang sering digunakan untuk pemasaran salah satunya adalah Instagram. Salah satu strategi yang digunakan dalam pemasaran produk adalah pemilihan konten-konten untuk di-post ke Instagram [8]. Antusisme para pelaku bisnis soal konten meningkat. Pasalnya, respon audience terhadap konten demikian cukup positif. Dimana 53\% waktu online mereka lebih banyak dihabiskan untuk "menikmati" konten. Dari sisi pelaku bisnis, kontenlah penyebab situs mereka mengalami kenaikan trafik pengunjung. Sampai-sampai, jumlah pengunjung naik 55\% lebih banyak dibanding sebelumnya [8][9]. Pertumbuhan user yang sebegitu masifnya membuat berbagai pihak "nimbrung" di dalamnya. Alhasil, persaingan antar konten pun tidak bisa dihindarkan lagi. Tercatat, ada 30 triliun foto (image) yang sudah terunggah di Instagram. Bila dihitung perhari, ada 70 juta foto perhari dan menghasilkan 2.5 miliar "like" perhari [9].

UMKM di Kecamatan Patuk menaungi 11 Desa, diantaranya Semoyo, Pengkok, Beji, Bunder, Nglegi, Putat, Nglanggeran, Salam, Patuk, Ngoro-oro, Terbah. Usaha yang dijalankan bergerak di bidang produk dan jasa, diantaranya: kerajinan, makanan seperti cokelat, rumput laut, dan lain sebagainya. Permasalahan yang ditemukan yaitu kurangnya kemampuan pelaku UMKM di Kecamatan Patuk dalam memasarkan produk menggunakan media online, seperti contoh melalui Instagram. Selain itu, terbatasnya informasi tentang 
bagaimana cara melakukan pemasaran konten melalui Instagram yang tepat guna dan sasaran oleh pelaku UMKM di Kecamatan Patuk untuk meningkatkan brand awarness dan brand recognition pada produk yang dijual melalui konten-konten yang di-publish melalui Instagram. Kegiatan pengabdian masyarakat dapat diwujudkan dalam bentuk pelatihan [10] dan pendampingan.

Berdasarkan uraian tersebut maka untuk meningkatkan pemasaran produk UMKM di Kecamatan Patuk diadakan pendampingan pelatihan pemanfaatan endorse dan hashtag untuk pemasaran produk menggunakan Instagram. Pendampingan ini bertujuan untuk membantu para pelaku UMKM di Kecamatan Patuk Kabupaten Gunung Kidul Daerah Istimewa Yogyakarta memanfaatkan endorse dan hashtag pada media sosial Instagram dalam memasarkan produk dengan tujuan untuk meningkatkan penjualan produk. Adapun pelaksana kegiatan pengabdian kepada masyarakat ini adalah Dosen Program Studi Teknik Informatika STTA Yogyakarta dan peserta pengabdian adalah pelaku UMKM di Kecamatan Patuk Kabupaten Gunung Kidul.

\section{Masalah}

Masalah-masalah prioritas yang dihadapi oleh mitra antara lain:

a. Kurangnya kemampuan pelaku UMKM di Kecamatan Patuk dalam memasarkan produk menggunakan media online yaitu Instagram, permasalahan ini diselesaikan dengan pendampingan pemanfaatan endorse dan hashtag menggunakan Instagram untuk memasarkan produk UMKM.

b. Terbatasnya informasi tentang bagaimana cara melakukan pemasaran melalui Instagram yang tepat sasaran dan dapat menjangkau masyarakat luas oleh pelaku UMKM di Kecamatan Patuk, permasalahan ini diselesaikan dengan pelatihan pemanfaatan endorse dan hashtag sebagai strategi peningkatan pemasaran dan penjualan produk menggunakan Instagram.

\section{Metode}

Berdasarkan pada uraian Permasalahan Prioritas Mitra, maka ditetapkan solusi yang ditawarkan untuk mengatasi permasalahan prioritas Mitra sebagai berikut:

a. Sumber Daya Manusia (SDM)

Metode yang dipilih untuk memenuhi kebutuhan SDM dengan melakukan pendataan terhadap pelaku UMKM di Kecamatan Patuk yang kurang mampu dalam memaksimalkan pemanfaatan endorse dan hashtag menggunakan Instagram dan kurangnya pemahaman tentang penggunaan media sosial Instagram sebagai salah satu media untuk pemasaran produk.

b. Proses

Pendampingan oleh pelaksana pengabdian masyarakat kepada pelaku UMKM di Kecamatan Patuk diawali dengan sosialisasi pengenalan Instagram, kemudian dilanjutkan dengan pendampingan dalam pemanfaatan endorse dan hashtag untuk pemasaran produk-produk UMKM serta penjelasan lebih lanjut mengenai penggunaan Instagram sebegai media pemasaran produk.

c. Produk

Menghasilkan pelaku UMKM di Kecamatan Patuk yang mampu memanfaatan Instagram untuk pemasaran produk dengan memaksimalkan kegiatan endorse dan hashtag untuk memasarkan produk-produk UMKM.

d. Manajemen 
Setelah melakukan sosialisasi, dilanjutkan dengan memberikan pendampingan pelaku UMKM di Kecamatan Patuk untuk dilatih dalam pemanfaatan endorse dan hashtag untuk pemasaran produk-produk melalui Instagram.

Kegiatan pengabdian kepada masyarakat dilaksanakan selama 3 hari sejak tanggal 17 Juni 2019 sampai dengan tanggal 19 Juni 2019 bertempat di Kantor Badan Kerjasama Antar Desa (BKAD) Kecamatan Patuk Kabupaten Gunung Kidul Daerah Istimewa Yogyakarta. Pada hari pertama, tanggal 17 Juni 2019, kegiatan yang dilakukan sebagai berikut:

a. Penjelasan tentang media sosial, dan Instagram.

b. Penjelasan tentang pemasaran produk menggunakan media sosial

c. Pelatihan pembuatan akun email dan akun Instagram

d. Penjelasan tentang konten-konten dalam Instagram

e. Pelatihan penggunaan Instagram

Pada hari kedua, tanggal 18 Juni 2019, kegiatan yang dilakukan sebagai berikut:

a. Penjelasan tentang endorse dan hashtag, contoh-contoh endorse dan hashtag, dan cara mencari endorse untuk Instagram

b. Pelatihan penggunaan endorse dan hashtag produk untuk pemasaran

Pada hari ketiga, tanggal 19 Juni 2019, kegiatan yang dilakukan sebagai berikut:

a. Pelatihan penggunaan endorse dan hashtag untuk pemasaran

b. Evaluasi hasil praktek penggunaan endorse untuk pemasaran

\section{Hasil dan Pembahasan}

Luaran dari kegiatan pengabdian kepada masyarakat ini adalah sebagai berikut:

a. Bertambahnya kemampuan dan ketrampilan pelaku UMKM di Kecamatan Patuk dalam memaksimalkan pemasaran produk melalui endorse dan hashtag pada Instagram untuk memperkenalkan produk kepada pelanggan dengan tujuan meningkatkan penjualan.

b. Meningkatnya kompetensi pelaku UMKM di Kecamatan Patuk dalam memanfaatkan Instagram sebagai media pemasaran.

Hubungan antara permasalahan mitra, solusi yang ditawarkan, dan target luaran kegiatan pengabdian ini dirangkum dalam Tabel 1.

Tabel 1. Permasalahan, Solusi yang ditawarkan dan Target Luaran Kegiatan

\begin{tabular}{c|l|l|l}
\hline No. & \multicolumn{1}{|c|}{ Permasalahan } & Solusi yang ditawarkan & \multicolumn{1}{c}{ Target Luaran } \\
\hline \hline 1. & $\begin{array}{l}\text { Kurangnya kemampuan pelaku } \\
\text { UMKM di Kecamatan Patuk } \\
\text { dalam memasarkan produk } \\
\text { menggunakan media online } \\
\text { yaitu Instagram. }\end{array}$ & $\begin{array}{l}\text { Mengadakan } \\
\text { pendampingan pemanfaatan } \\
\text { Instagram untuk } \\
\text { memaksimalkan kegiatan } \\
\text { endorse dan hashtag dalam } \\
\text { memasakan produk } \\
\text { UMKM. }\end{array}$ & $\begin{array}{l}\text { Bertambahnya kemampuan } \\
\text { pelaku UMKM di } \\
\text { Kecamatan Patuk dalam } \\
\text { memaksimalkan pemasaran } \\
\text { produk melalui endorse dan } \\
\text { hashtag pada Instagram } \\
\text { untuk memperkenalkan } \\
\text { produk kepada pelanggan } \\
\text { dengan tujuan } \\
\text { meningkatkan pemasaran } \\
\text { dan penjualan. }\end{array}$ \\
\hline
\end{tabular}


2. $\quad$ Terbatasnya informasi tentang bagaimana cara melakukan pemasaran konten melalui Instagram yang tepat guna dan sasaran oleh pelaku UMKM di Kecamatan Patuk untuk meningkatkan brand awarness dan brand recognition pada produk melalui Instagram.
Mengadakan pelatihan pemasaran produk-produk sebagai strategi peningkatan pemasaran dan penjualan produk menggunakan Instagram.
Meningkatnya kompetensi pelaku UMKM di Kecamatan Patuk dalam memanfaatkan Instagram sebagai media pemasaran.

Tabel 2 merupakan tabel yang menunjukkan evaluasi hasil peningkatan kemampuan dan ketrampilan pelaku UMKM di Kecamatan Patuk dalam pemanfaatan endorse dan hashtag untuk pemasaran dengan menggunakan Instagram.

Tabel 2. Hasil Pendampingan Kegiatan PKM Kecamatan Patuk

\begin{tabular}{|c|c|c|c|c|c|}
\hline \multirow{2}{*}{ No. } & \multirow{2}{*}{ Nama Peseta } & \multirow{2}{*}{ Asal UMKM } & \multicolumn{3}{|c|}{ Instagram } \\
\hline & & & Baik & Cukup & Kurang \\
\hline 1. & Partini & Elega Perca Bunder & $\sqrt{ } \checkmark$ & & \\
\hline 2. & Hemas Elega & Elega Perca Bunder & $\checkmark$ & & \\
\hline 3. & Wagiyem & Kembang Goyang \& Snack & & & $\checkmark$ \\
\hline 4. & Sri Lestari & Konveksi & $\checkmark$ & & \\
\hline 5. & Mustikah & Bonggol Pisang \& Peyek Kacang & $\checkmark$ & & \\
\hline 6. & Ernawati & $\begin{array}{l}\text { KWT SALAM } \\
\text { (Kunyit Instant) }\end{array}$ & $\checkmark$ & & \\
\hline 7. & Daliyah & Criping Pisang, Salak, Semoyo & $\checkmark$ & & \\
\hline 8. & Sri Yuntari & $\begin{array}{l}\text { Cripik Durian "Crian" } \\
\text { Sumbertetes }\end{array}$ & & $\checkmark$ & \\
\hline 9. & Endang Sri Lestari & $\begin{array}{l}\text { Sembako \& Kue Kering } \\
\text { Terbah }\end{array}$ & $\checkmark$ & & \\
\hline 10. & Sukisni & Criping Pisang "Kayugesit" & $\checkmark$ & & \\
\hline 11. & Wiwik Hikmawati & Criping Pisang \& Kulit Ikan Patin & $\checkmark$ & & \\
\hline 12. & Agus Purwanto & Popcorn & $\checkmark$ & & \\
\hline 13. & Nuri Setyawan & Gallery 99 & $\checkmark$ & & \\
\hline 14. & Wahyudi Nugroho & Packing Snack & $\checkmark$ & & \\
\hline 15. & Suharjono & Jahe Instant “ Mbah Parjo “ & $\checkmark$ & & \\
\hline 16. & Wiwit Puji Lestsri & $\begin{array}{l}\text { Coklat GUNKID Gambiran } \\
\text { Bunder }\end{array}$ & $\checkmark$ & & \\
\hline 17. & Umiyatun & Kerajinan Kayu Bobung & $\checkmark$ & & \\
\hline 18. & Suwarsih & Aneka Camila & & $\checkmark$ & \\
\hline
\end{tabular}

Ada 3 kriteria penilaian yaitu baik, cukup dan kurang. Dimana indikator penilaian 3 kriteria tersebut didasarkan beberapa hal yang didapat selama tiga hari pelatihan yaitu pembuatan akun email dan akun Instagram, pemanfaatan endorse dan hashtag pada Instagram, jumlah view dan likes setiap postingan endorse dan hashtag serta kreativitas masing-masing peserta UMKM dalam menghasilkan konten-konten yang siap dipasarkan pada Instagram.

Dilihat dari Tabel 2 Hasil Pendampingan Kegiatan PKM Kecamatan Patuk didapatkan bahwa $10 \%$ peserta pengabdian belum dapat memanfaatkan Instagram secara optimal 
dikarenakan peserta tersebut hanya datang pada hari pertama saja, 20\% peserta pengabdian sudah dapat memanfaatkan Instagram dengan baik namun belum optimal dalam menggunakan endorse dan hashtag, dan $70 \%$ peserta pengabdian sudah sangat optimal menggunakan Instagram dan memanfaatkan endorse dan hashtag.

Hasil pelatihan pemanfaatan endorse dan hashtag pada Instagram dapat dilihat pada Gambar 1 s.d. 7.

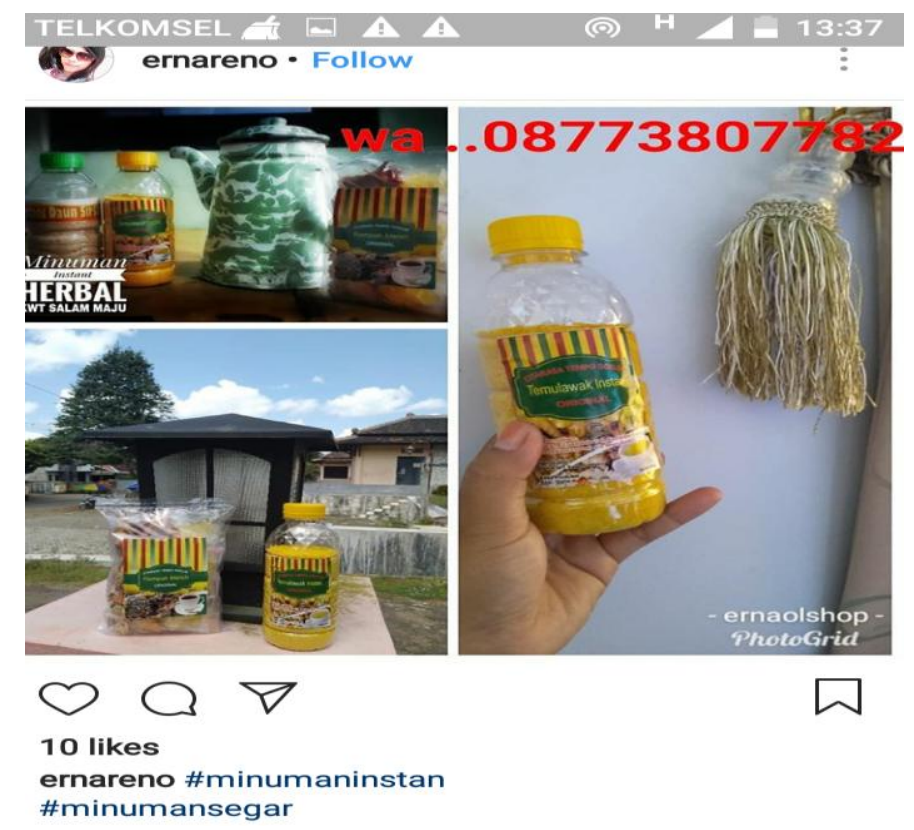

Gambar 1. Hasil Pemanfaatan Endorse dan Hashtag Minuman Instan

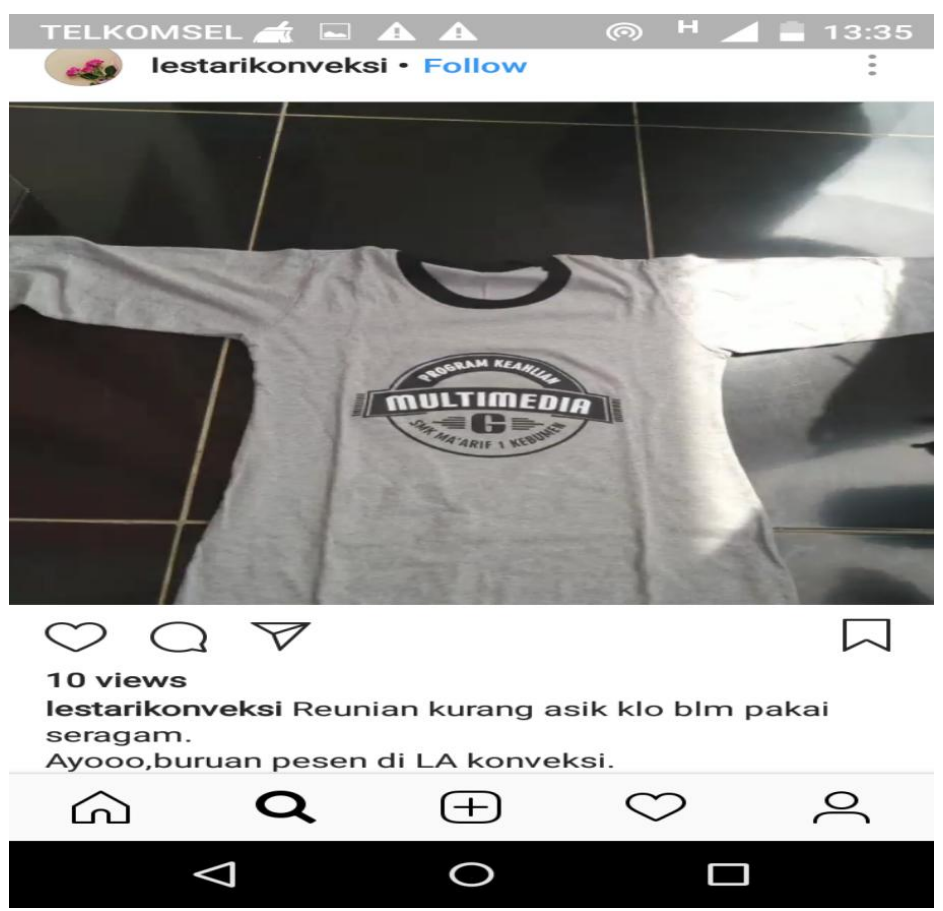

Gambar 2. Hasil Pemanfaatan Endorse Produk Kaos 
Pemanfaatan Endorse dan Hashtag untuk Pemasaran Produk Menggunakan Instagram...

(i) $\mathrm{O}$ https://www.instagram.com/p/BwzCrVtlcQf/ …句它

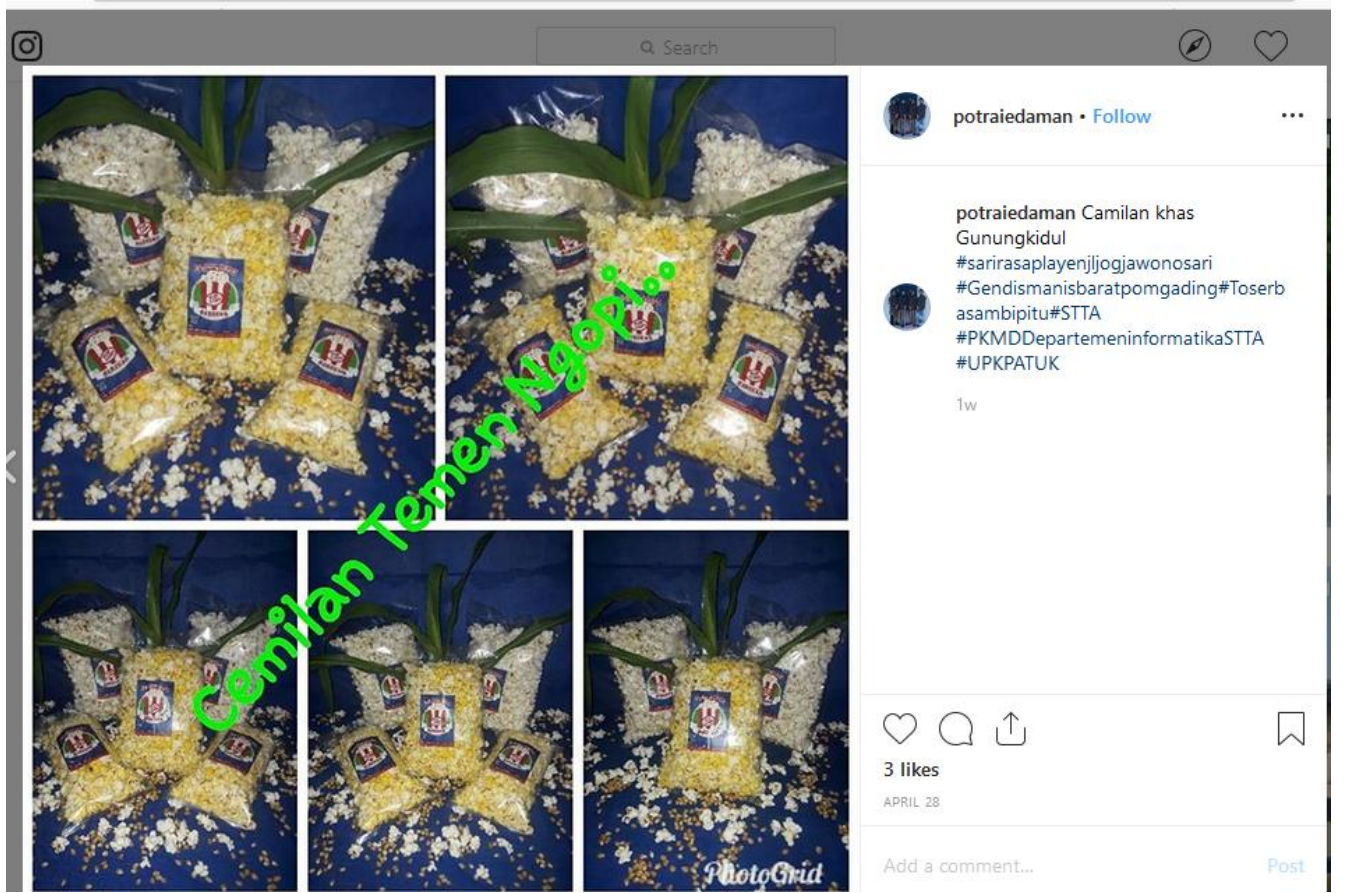

Gambar 3. Hasil Pemanfaatan Endorse dan Hashtag Produk Camilan

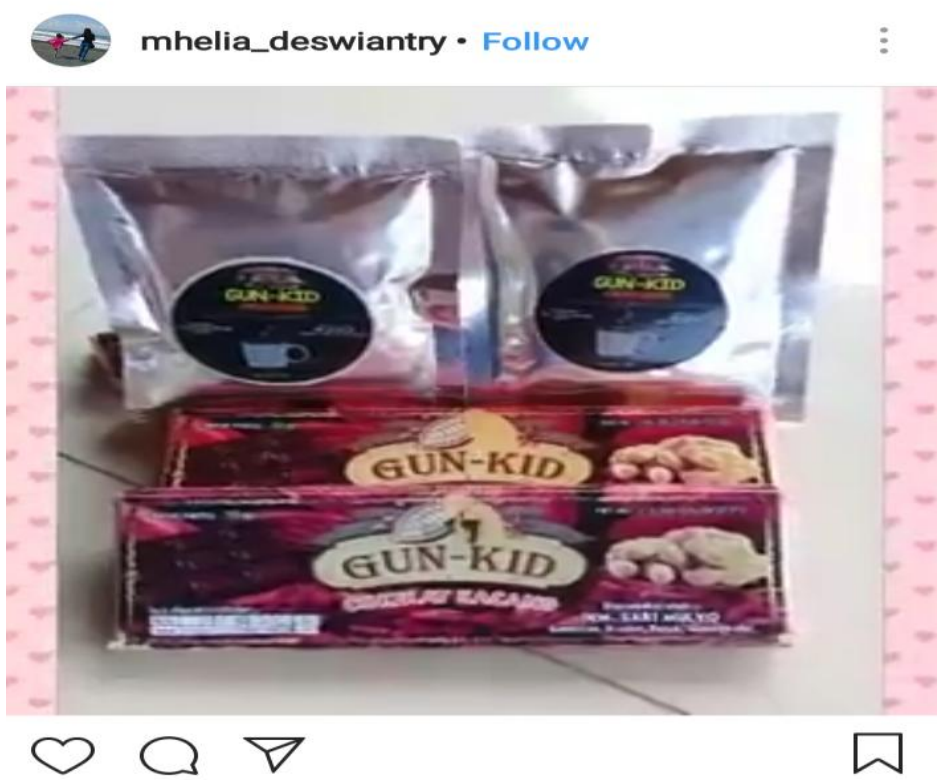

90 views

mhelia_deswiantry

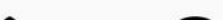

Gambar 4. Hasil Pemanfaatan Endorse Produk Coklat 


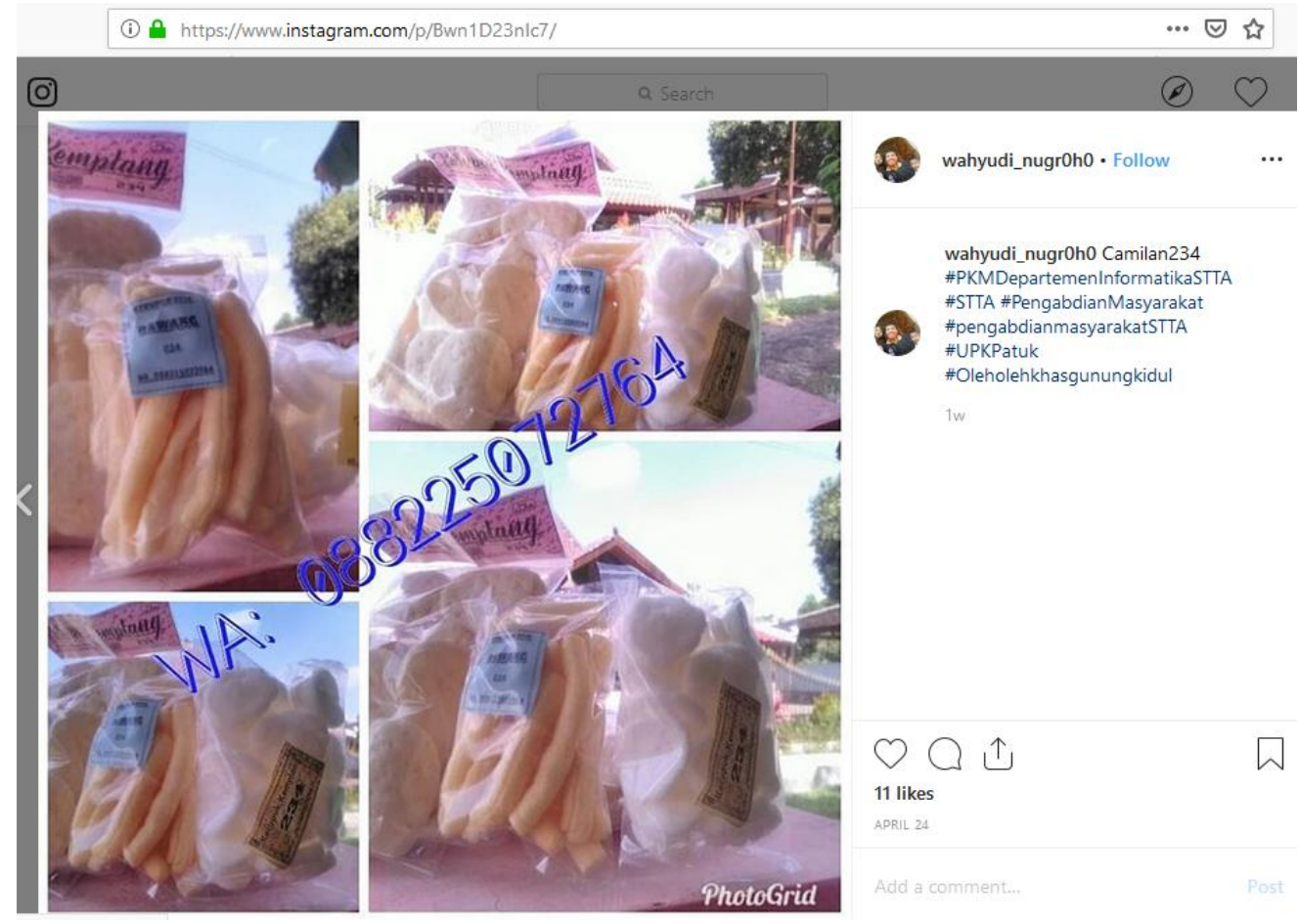

Gambar 5. Hasil Pemanfaatan Endorse dan Hashtag Produk Kerupuk

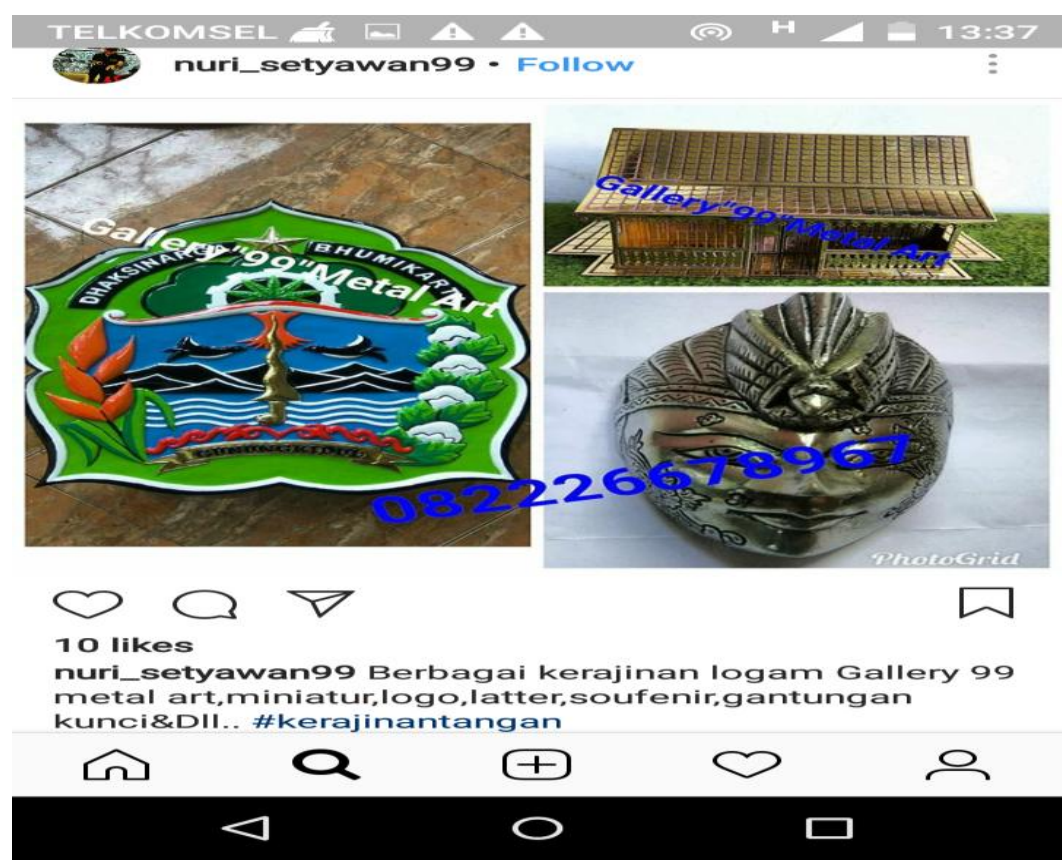

Gambar 6. Hasil Pemanfaatan Endorse dan Hashtag Kerajinan Logam 
Pemanfaatan Endorse dan Hashtag untuk Pemasaran Produk Menggunakan Instagram...

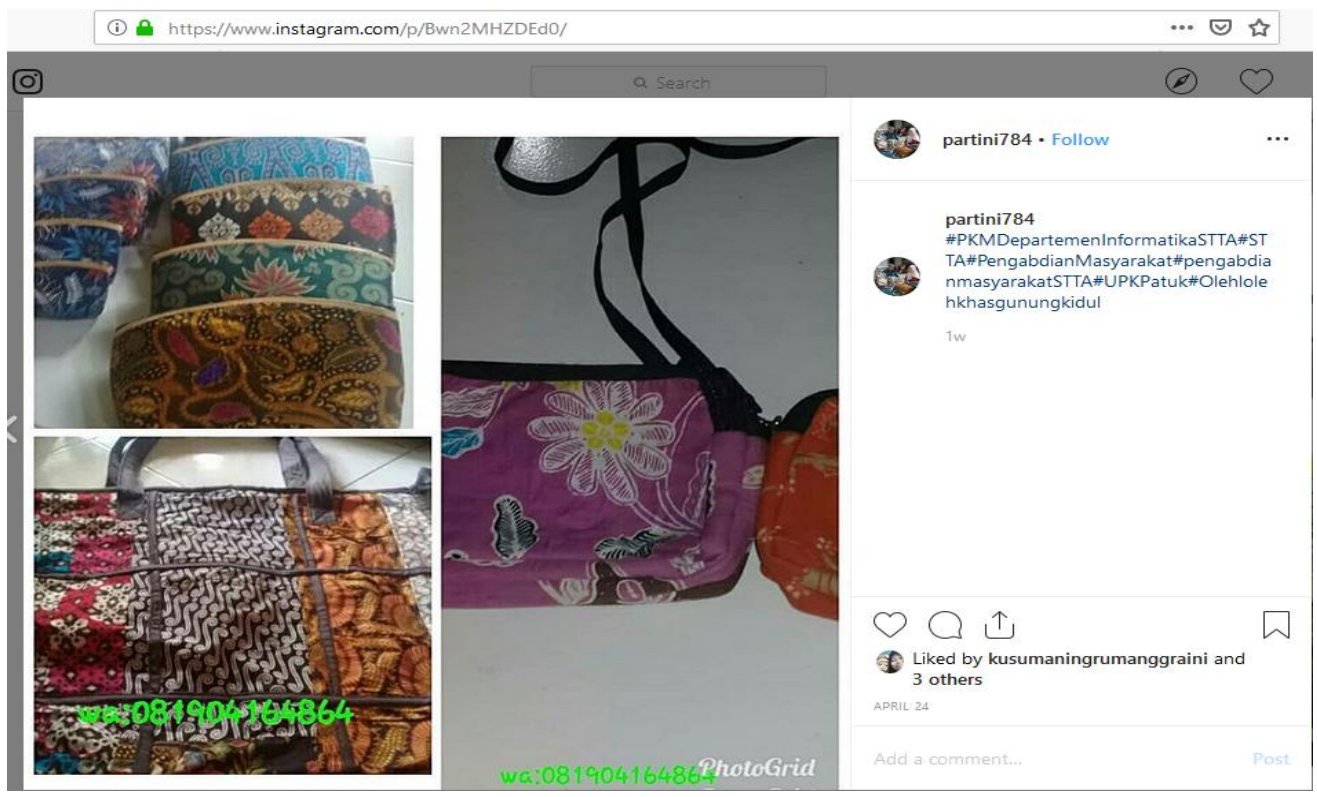

Gambar 7. Hasil Pemanfaatan Endorse Kerajinan Kain Perca

Foto dokumentasi saat pelatihan dan pendampingan kegiatan pengabdian pada masyarakat dapat dilihat pada Gambar 8 s.d Gambar 11 .

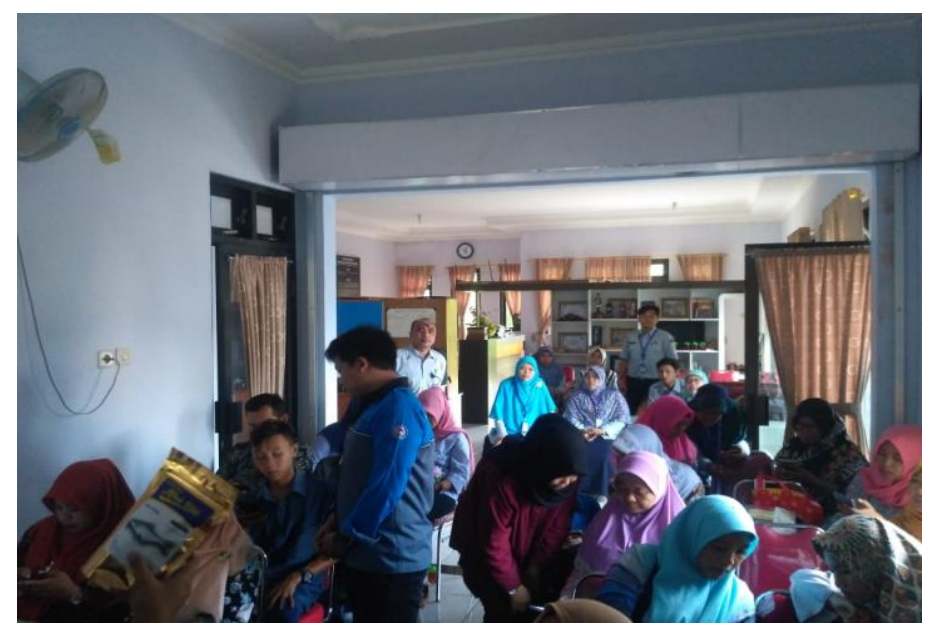

Gambar 8. Hari Pertama Kegiatan Pengabdian Masyarakat

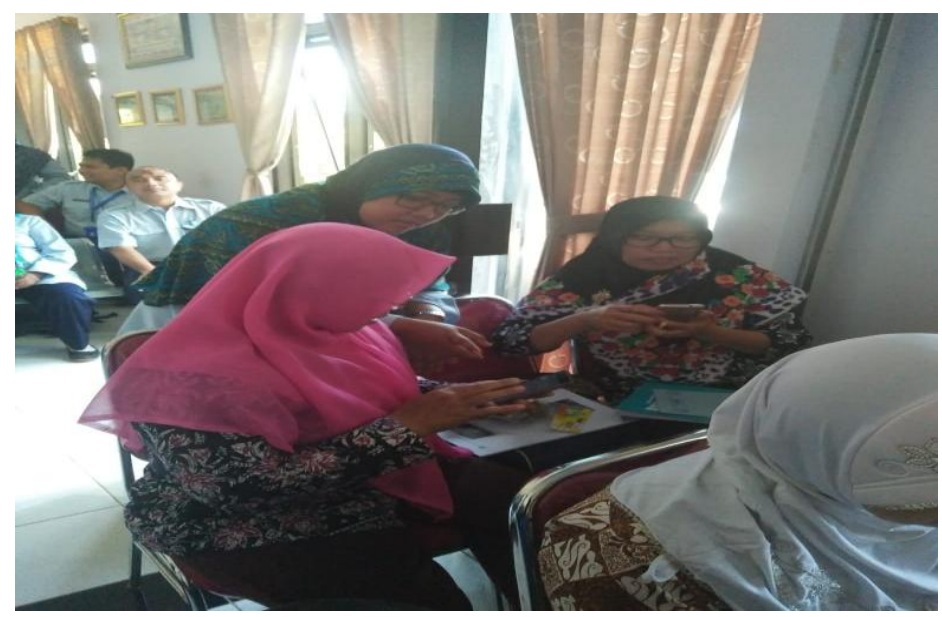

Gambar 9. Hari Kedua Kegiatan Pengabdian Masyarakat 


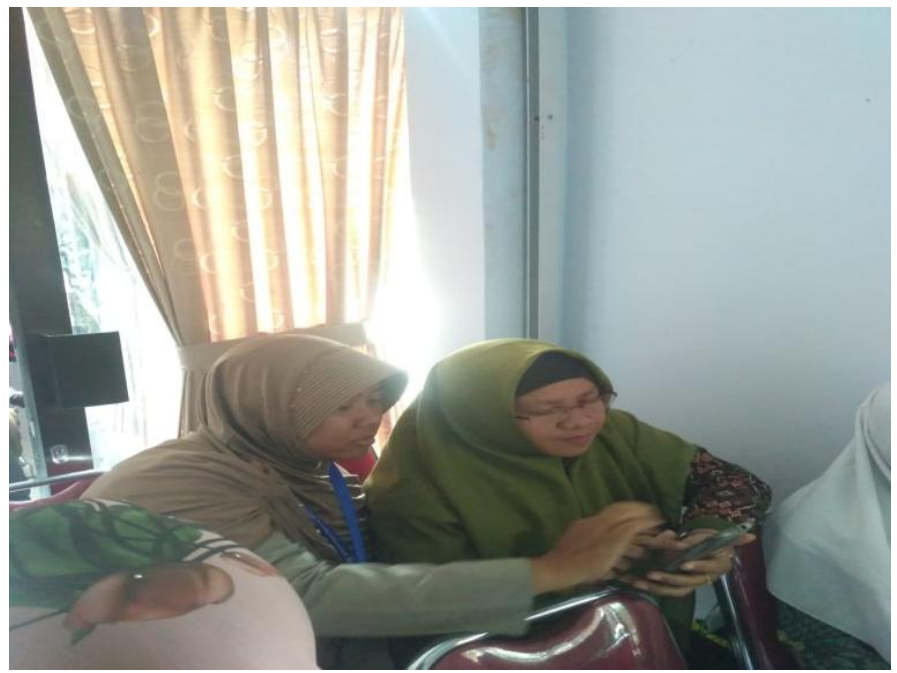

Gambar 10. Hari Ketiga Kegiatan Pengabdian Kepada Masyarakat

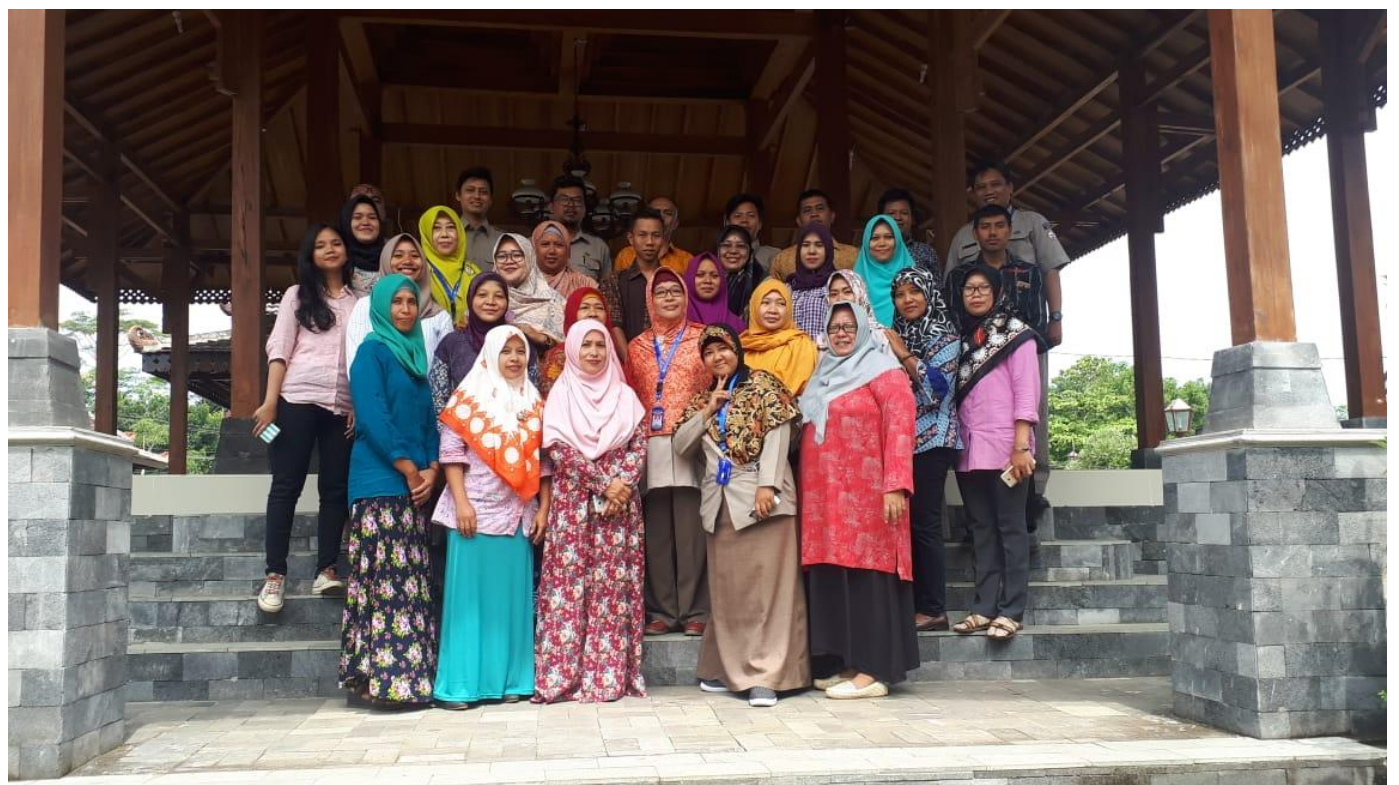

Gambar 11. Peserta dan Pelaksana Kegiatan Pengabdian Masyarakat Berfoto Bersama

\section{Kesimpulan}

Kegiatan pengabdian kepada masyarakat yang telah dilaksanakan dapat membantu para pelaku UMKM Kecamatan Patuk Gunung Kidul dalam menggunakan Instagram dengan memanfaatkan endorsement dan hashtag untuk media pemasaran online produk-produk UMKM.

\section{Daftar Pustaka}

[1]. Suci, Y. R. (2017). Perkembangan UMKM (Usaha mikro kecil dan menengah) di Indonesia. Cano Ekonomos, 6(1), 51-58.

[2]. Jauhari, J. (2014). Upaya pengembangan usaha kecil dan menengah (UKM) dengan memanfaatkan e-commerce. Jurnal Sistem Informasi, 2(1).

[3]. Pradiani, T. (2017). Pengaruh sistem pemasaran digital marketing terhadap peningkatan volume penjualan hasil industri rumahan. Jurnal Ilmiah Bisnis dan Ekonomi Asia, 11(2), 46-53. 
[4]. Kristiyanti, M. (2012). Peran strategis usaha kecil menengah (UKM) dalam pembangunan nasional. Majalah Ilmiah Informatika, 3(1), 63-89.

[5]. Retnowati, N. D., \& Retnowati, D. (2019). Pengolahan Dan Analisis Usaha Tanaman Jahe Menjadi Produk Jahe Instan Di Panti Asuhan Al-Ikhlas Ngentak Pelem RT. 13 Baturetno Banguntapan Bantul. KACANEGARA Jurnal Pengabdian pada Masyarakat, 2(2).

[6]. Indrianto, H., Susanto, I., \& Wijaya, A. F. (2016). Analisis Pemanfaatan Media Sosial Facebook Dalam Peningkatan Kinerja Promosi Pada Perguruan Tinggi (Studi Kasus: Fakultas Teknologi Informasi Universitas Kristen Satya Wacana Salatiga). SEMNASTEKNOMEDIA ONLINE, 4(1), 1-4.

[7]. Aryanto, S., Sudaryanto, S., Sajati, H., Kusumaningrum, A., Nugraheny, D., \& Wintolo, H. (2019). Pengembangan Kewirausahaan Bagi UP2K-PKK Kelurahan Prawirodirjan Gondomanan Yogyakarta Untuk Mendukung Pemasaran Produk Menggunakan Instagram. KACANEGARA Jurnal Pengabdian pada Masyarakat, 2(2).

[8]. Pratiwi, E. D. (2016). Faktor yang Mempengaruhi Niat Menggunakan Instagram dengan The Theory Of Reasoned Action Menggunakan Amos 21. Jurnal Teknik Komputer, 2(1), 68-77.

[9]. Kertamukti, R. (2015). INSTAGRAM DAN PEMBENTUKAN CITRA (Studi Kualitatif Komunikasi Visual dalam Pembentukan Personal Karakter Account Instagram@ basukibtp).Profetik, 8(1).

[10]. Ayuningtyas, A., Retnowati, N. D., Pujiastuti, A., Indrianingsih, Y., \& Honggowibowo, A. S. (2019). Pelatihan Mendesain Artikel Artistik Menggunakan Microsoft Word Bagi Kelas 5 SD di SDIT Salsabila Al Muthi'in Yogyakarta. KACANEGARA Jurnal Pengabdian pada Masyarakat, 2(1), 13-20. 
Nurcahyani Dewi Retnowati, Yuliani Indrianingsih, Anton Setiawan Honggowibowo 